\title{
Erratum to: The Global Anticoagulant Registry in the FIELD - Atrial Fibrillation (GARFIELD-AF): Exploring the changes in anticoagulant practice in patients with non-valvular atrial fibrillation in the Netherlands
}

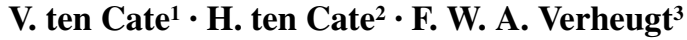

Published online: 10 November 2016

(C) The Author(s) 2016. This article is available at SpringerLink with Open Access.

\section{Erratum to:}

Neth Heart J (2016)

DOI: 10.1007/s12471-016-0874-y

In the version of the article originally published online, there was an error in the acknowledgement section. The authors wrote: 'and Dr. S.H.K. The (Bethesda Diabetes Research Center)'. The line should have read: 'and Dr. S.H.K. The (Treant Zorggroep - locatie Bethesda)'.
Open Access This article is distributed under the terms of the Creative Commons Attribution 4.0 International License (http:// creativecommons.org/licenses/by/4.0/), which permits unrestricted use, distribution, and reproduction in any medium, provided you give appropriate credit to the original author(s) and the source, provide a link to the Creative Commons license, and indicate if changes were made.

The online version of the original article can be found under DOI 10.1007/s12471-016-0874-y.

V. ten Cate

vincent.ten.cate@mumc.nl

1 Laboratory for Clinical Thrombosis and Haemostasis, Cardiovascular Research Institute Maastricht, Maastricht, The Netherlands

2 Department of Internal Medicine, Cardiovascular Research Institute Maastricht, Maastricht, The Netherlands

3 P.C. Hooftstraat 188, $1071 \mathrm{CH}$ Amsterdam, The Netherlands 